\title{
COMPORTAMENTO PARENTAL E O PAPEL DO PAI NO DESENVOLVIMENTO INFANTIL
}

\section{PARENTAL BEHAVIOR AND THE ROLE OF FATHER IN THE CHILD DEVELOPMENT}

\author{
Edi Cristina Manfroi ${ }^{1}$ \\ Samira Mafioletti Macarini ${ }^{2}$ \\ Mauro Luis Vieira ${ }^{3}$
}

Manfroi EC; Macarini SM; Vieira ML. Comportamento parental e o papel do pai no desenvolvimento infantil. Rev. Bras. Cresc. e Desenv. Hum. 2011; 21(1): 59-69

\section{Resumo:}

Este artigo tem o objetivo de discutir o cuidado parental e o papel do pai no desenvolvimento infantil, a partir da perspectiva teórica da psicologia evolucionista. O cuidado parental foi abordado enfatizando-se seu caráter interacionista, com relação a seus aspectos biológicos e culturais. Além das especificidades do papel dos pais no comportamento parental, foram discutidas as características das crianças que influenciam neste cuidado. Na última seção do artigo foram focalizadas as características do cuidado paterno e sua influência no desenvolvimento infantil. Concluiu-se o cuidado parental tem especificidades em relação ao comportamento da mãe e do pai, que podem ser explicadas pelas perspectivas biológicas e culturais. Nesse sentido, para se compreender o comportamento parental é necessário considerar a história filogenética de espécie humana e também o contexto histórico e sociocultural onde a família está inserida.

Palavras-chave: cuidado parental; comportamento parental; psicologia evolucionista; cuidado paterno; pai.

\begin{abstract}
:
This paper aims to discuss the parental care and the role of the father in child development in early years, from the perspective of evolutionary psychology. The parental care was discussed emphasizing its characteristic of interaction, with respect to biological and cultural aspects. In addition to the role of parents in parental behavior, it was discussed the characteristics of children that influence the parental care. In the last section of the article, the focus was on the role of the father in parental care and its influence on child development. It has been concluded that parental care is specific to the behavior of the mother and father, which can be explained by biological and cultural perspectives. In this way, to understand the parental behavior is necessary to consider both the phylogenetic history of human species and also the socio-historical context where the family is inserted.
\end{abstract}

Key words: parental care; parental behavior; evolutionary psychology; father care; father.

\footnotetext{
Psicóloga, doutoranda pelo Programa de Pós-graduação em Psicologia da Universidade Federal de Santa Catarina. Psicóloga, Mestra pelo Programa de Pós-graduação em Psicologia da Universidade Federal de Santa Catarina.

Professor Doutor Associado do Departamento de Psicologia da Universidade Federal de Santa Catarina. Pesquisador CNPq. Correspondência para: Universidade Federal de Santa Catarina, Departamento de Psicologia. Núcleo de Estudos e Pesquisas em Desenvolvimento Infantil - NEPeDI. Campus Universitário, Trindade, Florianópolis - SC http://www.nepedi.ufsc.br - E-mail: maurolvieira@gmail.com CEP: 88040-900.
} 


\section{INTRODUÇÃO}

O estudo do cuidado parental tem sido de interesse de pesquisadores por um longo tempo. Parte desse interesse é motivado pela existência de diferentes teorias que procuram investigar a natureza das situações vividas durante a infância e os possíveis efeitos que possam ter sobre as esferas cognitiva, emocional e social no desenvolvimento da criança. Além disso, deve-se considerar que durante o desenvolvimento inicial, a criança, em função de sua dependência e imaturidade, necessita de cuidados e da presença de adultos para garantir sua sobrevivência. Nesse sentido, o papel dos pais torna-se fundamental.

Entende-se que a relação que os pais estabelecem com seus filhos depende de variáveis individuais dos mesmos e da sua prole (fatores biológicos adaptados na história evolucionária da espécie) e também de variáveis sociais e ambientais, entendidas como pressões culturais que atuam sobre e são influenciadas pelas bases biológico-adaptativas do comportamento parental, modulando sua expressão individual ${ }^{1}$. No entanto, o que tem sido verificado é que, em geral, os estudos sobre cuidados parentais focalizam sua investigação mais especificamente na mãe, em detrimento do pai.

Este artigo tem como objetivo discutir o cuidado parental, bem como o papel do pai no desenvolvimento infantil durante os primeiros anos, utilizando-se como perspectiva teórica a psicologia evolucionista. Para isso, primeiramente o cuidado parental será abordado enfatizando-se seu caráter interacionista, com relação a seus aspectos biológicos e culturais. $\mathrm{Na}$ segunda parte serão apresentadas as características dos lactentes que influenciam nesse cuidado. E, por último, serão focalizadas mais especificamente as características do cuidado paterno e sua influência sobre8kjnn mkmbhlnm ,n desenvolvimento infantil.

\section{Cuidado parental: aspectos biológicos e culturais}

Atualmente, é possível verificar a convergência de uma postura interacionista nas diversas abordagens teóricas que visam compreender o cuidado parental. Os termos maternidade e paternidade designam muito mais do que mera capacidade biológica de gerar, significando também responsabilidades sociais que apresentam conotações distintas conforme o gênero: a mãe, podendo ser biológica ou não, é responsável pelo bom desenvolvimento da criança, pela sua educação, alimentação, saúde; enquanto que o pai é visto como responsável por prover as necessidades materiais da família, sendo seu condutor moral. Constata-se que os papéis de pai e mãe englobam significados que são construções socioculturais, e, por isso, fortemente influenciadas pela constituição das identidades e dos papéis de gênero, mas que também apresentam aspectos biológicos, isto é, características que foram selecionadas na história de evolução da espécie ${ }^{1}$.

Nesse sentido, para uma compreensão do comportamento parental a partir de uma perspectiva evolucionista, faz-se necessário levar em consideração seus aspectos causais próximos e últimos. As explicações próximas consistem em fatores imediatos que modulam as respostas comportamentais, tais como estímulos fisiológicos, condições ambientais atuais, período sócio-histórico e estados psicológicos. Por sua vez, as explicações últimas consistem em características da espécie, presentes no organismo (sensibilidade diferencial aos estímulos, tendências motivacionais específicas, períodos sensíveis e pré-organização de processos de aprendizagem), que surgiram em um determinado momento da história evolucionária e serviram para a melhor adaptação do organismo ao ambiente em que ele estava inserido e, por esse motivo, se mantiveram dentro do repertório comportamental da espécie². 
Com relação às causas últimas, pode-se pensar que o comportamento parental foi selecionado por possuir uma função de sobrevivência na história de evolução da espécie. Ou seja, a psicologia evolucionista considera que o cuidado parental diz respeito a qualquer comportamento que aumente a aptidão do filhote, mais especificamente com relação a sua sobrevida e taxa de reprodução, advindas do cuidado recebido ${ }^{3}$. Além disso, o cuidado parental deve ser compreendido a partir de mecanismos inatos, selecionados ao longo da história da espécie, os quais evoluíram simultaneamente com o grau do desenvolvimento dos filhotes ${ }^{6}$. No caso da espécie humana, em que o recém-nascido nasce bastante imaturo e dependente para sobreviver, o cuidado de um adulto tornou-se fundamental.

Na teoria do investimento parental de Trivers ${ }^{3}$, o autor discute o nível de desenvolvimento do filhote ao nascer e o quanto o mesmo exigirá de energia dos cuidadores ao longo do desenvolvimento inicial. Assim, considerase haver um equilíbrio entre investimento parental e estado inicial de desenvolvimento, o qual pode ser caracterizado nas diferentes espécies como altricial, precoce ou misto. Resumidamente, nas espécies altriciais, o período de gestação é curto e os filhotes nascem bastante imaturos do ponto de vista dos sistemas sensorial e termorregulador, e necessitam de cuidados diretos para se alimentar e sobreviver. Nas espécies precoces, por sua vez, o período de gestação é longo e os filhotes nascem com capacidades adaptativas especializadas - como a visão, audição, sistema termorregulador e motor -

as quais lhes garantem maior autonomia e, portanto, demandam um cuidado parental menos intenso e prolongado, com menor dispêndio de energia para os cuidadores.

Por fim, nas espécies mistas a gestação é longa e o recém-nascido apresenta um equipamento neurossensorial inato especializado, possuindo inúmeras habilidades, mas, ao mesmo tempo, dependendo de um adulto para garantir sua sobrevivência. Tais espécies exigem cuidados intensos e prolongados, dado o fato de nascerem imaturos, mas são capazes de ativamente desencadear e regular os cuidados parentais desde o momento do nascimento. Os humanos enquadram-se nessa categoria ${ }^{4,5,6}$.

Outro fator que interfere no cuidado parental consiste no equilíbrio entre o esforço no acasalamento (gastos na procura de oportunidades reprodutivas) e o esforço no nascimento e cuidado dos filhos, o qual implica um custo energético específico ${ }^{6}$. Assim, pode-se afirmar que o grau de investimento no acasalamento e no cuidado parental irá variar entre espécies e entre machos e fêmeas, conforme as características de desenvolvimento dos filhotes e das características ecológicas presentes. No caso das mulheres, existe um custo energético muito mais alto para o acasalamento e cuidado dos filhos, por meio da gravidez e lactação, o que lhe garantirá uma estratégia diferenciada da dos homens. Além disso, mães e pais investem de forma diferenciada $^{3}$, uma vez que o fornecimento de cuidado nessas espécies está condicionado à certeza da maternidade/paternidade. $\mathrm{O}$ fato de a gestação ocorrer no organismo materno garante à mãe a certeza de estar investindo em seus descendentes, enquanto que para o pai essa certeza é mais difícil de ser obtida.

O custo enérgico indireto em fêmeas e machos está relacionado ao despêndio de tempo, horas de sono, limpeza, transporte, controle de temperatura corporal, o que torna esse tipo de cuidado típico de um investidor de longo prazo. Assim, os machos, para garantir o seu sucesso reprodutivo e de sua espécie, necessitam enfrentar um dilema promovido pela força da seleção natural: gastar sua energia no esforço de cuidado à prole ou no esforço de acasalamento ${ }^{3}$. Caso se dedique ao cuidado parental, precisará aumentar as chances de garantir que o filhote no qual está investindo carregue seus genes, por meio de estratégias que 
se mostraram úteis na evolução: permanecendo próximo à prole e a mãe e auxiliando na sua proteção e sustento. Caso se decida pelo esforço do acasalamento terá que enfrentar disputas com outros machos para ter acesso às fêmeas disponíveis, as quais poderão colocar em ameaça sua própria sobrevivência ou que poderão limitar suas chances de deixar descendentes asseguradamente seus.

Segundo De Waal ${ }^{7}$, a família nuclear é a marca registrada da evolução social humana, uma vez que ao optar pela monogamia, o homem aumentou a capacidade de distinguir quais filhos são realmente seus descendentes. Assim, a família nuclear teria se originado a partir de uma tendência do macho a acompanhar a fêmea com quem se acasalou para manter rivais e infanticidas à distância e, ao mesmo tempo, estabelecer uma sociedade cooperativa na qual ambos os sexos se sentiam seguros. Além disso, aumentando a certeza da paternidade, abriuse caminho para um envolvimento ainda maior do pai nos cuidados dos filhos; sendo estes tanto indiretos, como a provisão de alimentos e proteção da prole, quanto um investimento mais direto de cuidado por meio da alimentação, limpeza e transporte ${ }^{8}$. Nesse aspecto a divisão do trabalho entre machos e fêmeas e a monogamia podem ter surgido para resolver um problema de sobrevivência da espécie entre humanos.

Entretanto, apesar da presença do pai nas famílias, o que diversos autores têm destacado é que as mães se caracterizam como as principais cuidadoras e, consequentemente, a primeira figura de apego durante o primeiro ano de vida do lactente ${ }^{9,10}$. Segundo Keller ${ }^{9}$, tal fato encontra respaldo na explicação da história filogenética da espécie, uma vez que o ser humano é um mamífero e o aleitamento materno é um dos responsáveis pela dependência do bebê em relação a figura materna. Hoje em dia existem várias formas e alternativas para cuidar dos filhos. No entanto, durante a maior parte da nossa história enquanto espécie, a mãe teve papel decisivo no cuidado à criança durante os anos iniciais de vida.

Portanto, o componente biológico do comportamento é mais bem compreendido mediante análise do contexto no qual está inserido; ao mesmo tempo em que a construção cultural deste comportamento é mais bem entendida, em relação à disposição inata do homem de se organizar em grupos cooperativos para suprir necessidades biológicas de cuidado, alimentação e proteção ${ }^{1}$.

No caso da mulher, a ligação entre mãe e filho pode ser facilmente explicada. Os processos básicos envolvidos na maternidade como as fortes estimulações ligadas à gestação, ao parto e à amamentação seriam desencadeantes de uma série de respostas comportamentais, contribuindo para a formação de um vínculo positivo ${ }^{11}$. Além disso, sabe-se que o recém-nascido possui características que facilitam esta relação, principalmente pela da amamentação, em que há um contato direto com a mãe por meio do olhar, vocalização, toque e o calor do corpo na díade. Segundo os autores retrocitados não existe nada que explique as mesmas estimulações nos pais.

Outro fator que envolve a relação de proximidade entre díade mãe-filho são os cuidados de higiene desempenhados pelas mães, que na sua maioria não permitem que os homens o façam. Tal prática poderia ser explicada pelo sistema de crenças aprendidas por elas com sua família de origem ${ }^{12}$. Além disso, deve-se levar em conta também que na sociedade brasileira o pai não recebe afastamento remunerado do seu trabalho como acontece com a mãe, que tem o direito de permanecer com o filho por um período de no mínimo quatro meses de licença maternidade.

Por esta razão, de acordo com Maldonado, Dickstein e Nahoum ${ }^{13}$, muitas vezes o pai não consegue criar um vínculo concreto e sólido com a criança, sendo esse processo mais lento e consolidando-se gradualmente após o nascimento e no decorrer de seu 
desenvolvimento. No entanto, constata-se que existe uma explicação para a determinação da sensibilidade masculina ao investimento e responsividade paterna ${ }^{11}$. Bandeira et $\mathrm{al}^{11}$, procuraram identificar na literatura se a proximidade entre "casais grávidos" poderia ter influência na preparação do homem para a paternidade. Os resultados encontrados indicaram que em culturas que apresentam cuidado parental e alto nível de intimidade entre casais foram constatados sintomas como náuseas e variações de peso, oscilações de apetite, fadiga e mudanças emocionais nos homens durante a gestação da mulher. Concluiu-se também que nesses casais ocorrem alterações dos hormônios, uma vez que ambos apresentam aumento da concentração de prolactina e diminuição na concentração de esteróides sexuais, tais como a testosterona e o estradiol. É possível que esse fator possa influenciar o desenvolvimento do vínculo entre pai e filho mais cedo que normalmente ocorre.

Portanto, pode-se pensar que alguns dos fatores proximais que influenciam a construção social da maternidade e paternidade são: a relação familiar (com o pai, com a mãe e depois com o próprio cônjuge); as condições sociais e econômicas; a relação com o grupo de pares etc. A estrutura sociocultural de uma dada sociedade marca a vida de homens e de mulheres e por consequência exerce efeito sobre os papéis parentais, até mesmo na disponibilidade de tempo para se dedicar aos filhos e à família. Algumas tarefas com relação aos filhos e à casa demandam mais tempo do que outras, influenciando a divisão social e sexual do trabalho ${ }^{14}$. Da mesma forma que certos valores e costumes estabelecem expectativas com relação à masculinidade e à paternidade.

Sabe-se que os recém-nascidos necessitam de cuidados por um longo período, e isso depende da manutenção da proximidade de adultos que desempenhem funções de proteção e fornecimento de alimento e segurança, que garantam a sobrevivência dele. Deste modo, o quão aptos estão os progenitores para interagir com a criança passa a ser um elemento importante para garantir um desenvolvimento saudável. No entanto os pais não são os únicos responsáveis pelo sucesso dessa relação, tendo a criança um papel importante para a formação e manutenção do apego. Uma vez que são indefesas, necessitam atrair e manter a atenção do ambiente social para que sejam cuidadas ${ }^{9}$. Com isso, entende-se que as características e a capacidade do lactente de interagir com os seus cuidadores é de fundamental importância para o desenvolvimento do apego seguro e da responsividade.

\section{Características dos recém-nascidos e o cuidado parental}

O recém-nascido quando nasce apresenta motivações sensório-perceptivas que o ajudam na formação do vínculo com seus cuidadores ${ }^{6}$. É dotado de características e capacidades inatas que possibilitam uma interação dinâmica entre ele e o seu contexto, com a finalidade de desenvolver o vínculo entre as pessoas que o cercam, promovendo dessa forma o engajamento dos adultos nos cuidados necessários para sua sobrevivência no contexto atual. Tais características são compreendidas pela Psicologia Evolucionista como parte do repertório selecionado filogeneticamente pela evolução da espécie no decorrer da história.

Entre os humanos, fatores que interferem e eliciam os cuidados parentais correspondem a características de neotenia e sinais específicos que os recém-nascidos emitem ao nascer ${ }^{6,5,15}$. A neotenia diz respeito à retenção ou manutenção de aspectos juvenis/fetais, como nascer com poucos pêlos, crânios grandes, faces arredondadas, manutenção do perfil reto, dentes e maxilares pequenos, testa pouco protuberante ${ }^{6}$. A neotenia está relacionada a um aumento de volume do cérebro no nascimento, associado à evolução da posição bípede, o que favoreceu a seleção natural de fêmeas que davam à luz recém-nascidos ainda imaturos do ponto de vista neurológico ${ }^{2}$. Tais característi- 
cas são consideradas atrativas e agem como eliciadores da responsividade e do cuidado parental.

Além disso, são capazes de atrair a atenção dos adultos através de traços denominados "esquemas infantis" ou kindchenschema $a^{9}$. 5,15. Dentre tais características podem-se citar: cabeça relativamente grande comparada com o tamanho do corpo, face redonda, bochechas grossas, olhos grandes e implantados para baixo, testa proeminente, extremidades curtas e grossas e movimento desajeitados. Segundo Seidl de Moura et $\mathrm{al}^{5}$, a organização de tais traços dão uma aparência atraente e agradável de aconchego, eliciando respostas de cuidado e proteção nos adultos.

Partindo-se da perspectiva evolucionista, constata-se que nasce com algumas habilidades que foram selecionadas ao longo do período de evolução por garantir maior possibilidade de adaptação e sobrevivência da espécie no período inicial do desenvolvimento, tais como: vocalização, expressões faciais, audição, visão, discriminação olfativa, preferência por faces e pela voz humana etc ${ }^{5}$. Para Ribeiro et $\mathrm{al}^{16}$, os lactentes possuem capacidades para perceber o ambiente físico e também psicológico dos seres humanos, e se engajam em uma interação recíproca de relação de apego através da orientação da voz e face humana em especial a face feminina.

Pesquisas foram realizadas com o objetivo de identificar essas características dos recémnascidos e indicam que teriam capacidade de identificar mesmo no período de gestação a voz da mãe e dirigem mais atenção para o rosto materno do que para um estranho mesmo quando a informação olfativa é controlada ${ }^{5}$. Essa capacidade do recém-nascido seria uma das muitas evidências que comprovam a relação de reciprocidade entre mãe-filho. Além disso, ele consegue enxergar a $20 \mathrm{~cm}$ de distância, espaço que normalmente fica seu rosto com o de sua mãe na hora da amamentação, facilitando o desenvolvimento do vínculo afetivo.
Entende-se, com isso, que a responsividade envolvida no cuidado parental inclui alguns aspectos como a ação das crianças, a ação dos pais e o reflexo desta sobre a criança. Isto envolve, segundo Ribas, et $\mathrm{al}^{17}$, duas principais dimensões: uma temporal e outra qualitativa. A temporal é considerada a contingência de resposta, ou seja, o quanto as ações do lactente vão ser contingentes à resposta de cuidado apresentada pelos pais. Já na dimensão qualitativa estão incluídas características como o calor, a proximidade, intimidade, que em geral remetem ao afeto.

Contudo, quando se parte da perspectiva evolucionista, logo se pensa que todo o comportamento foi selecionado filogeneticamente e possui uma função para a sobrevivência da espécie, no entanto, a história ontogenética de cada um tem papel importante na ativação destes processos ${ }^{6,16,24}$. Portanto, ainda que a história filogenética possua um papel importante na constituição do apego e vínculo entre mãe e filho, ao contrário do pai, que por conta das características biológicas e filogenéticas não tenha se desenvolvido, não se pode pensar que o homem não tenha essa capacidade. É necessário também levar em conta os aspectos proximais do comportamento parental, os quais podem reforçar a participação do pai nos cuidados para com os filhos. Segundo Lamb ${ }^{10}$ também o pai, e não apenas a mãe, seria capaz de desenvolver vínculos de apego com seus filhos, ainda que com capacidades de responsividade e sensibilidade diferenciadas, e que o seu papel seria relevante para a criança, tanto no seu curso de desenvolvimento normal quanto patológico.

\section{O papel do pai no desenvolvimento infantil}

A despeito de a responsividade envolvida no cuidado parental ser definida como a capacidade do progenitor de mostrar-se sensível aos sinais da criança ${ }^{18}$, e apesar da mãe ser a principal figura de apego, Prado e Vieira ${ }^{6}$ enfatizam que o pai merece atenção especial, 
não como reflexo ou substituição da relação de apego do filho com a mãe, mas como de fundamental importância para o desenvolvimento da criança.

Como exemplo da relação que o pai pode contribuir ao nascimento do filho, é possível citar não somente o apoio material, mas também o suporte emocional à gestante que se constitui em uma importante função atribuída ao $\mathrm{pai}^{19}$. Nesse sentido, segundo os autores, a aceitação do filho pelo companheiro é um fator significativo para o desenvolvimento do apego materno à criança. Sua ajuda se dá, principalmente, através do apoio à mulher na harmonização de seus conflitos em torno da maternidade.

Apesar das mudanças em nossa sociedade a interação entre pai e mãe no ambiente familiar é distinta e os esforços deles teriam que ser no sentido de dividir responsabilidades em relação aos cuidados dos filhos ${ }^{18}$. Sendo assim, compreender as diferenças entre homens e mulheres com relação ao que eles atribuem ser de responsabilidade do pai na criação dos filhos é uma forma de investigar a interação pai-criança.

Paquette ${ }^{20}$ desenvolveu alguns estudos a respeito do comportamento paterno e o desenvolvimento infantil e enfatiza que o pai é mais do que um simples coadjuvante dessa relação. Para o autor, ambos os pais estão implicados em duas dimensões-chave de cuidados parentais, uma emocional e a outra de controle, sendo que cada um (pai e mãe) atua do seu próprio modo. Contudo, em geral, as mães são mais compreensivas e afetuosas, enquanto que os pais obtêm a obediência das crianças mais facilmente por meio de sua autoridade persuasiva, exercendo assim, o controle. O mesmo autor argumenta que tanto a figura materna como a paterna asseguram a proteção da criança, mas com um equilíbrio diferente. A mãe tende a acalmar a criança quando ela esta agitada e aflita, ao passo que o pai tende a colocar a criança em situações nas quais ela é obrigada a confrontar o ambiente circundante, fornecendo, ao mesmo tempo, proteção e impondo limites.

Nessa perspectiva, Paquette ${ }^{20}$ enfatiza que o papel do pai é tão importante quanto o da mãe no desenvolvimento infantil, sendo que cada um funcionaria em polos distintos. O primeiro polo, caracterizado pela relação de anexo exercida pela mãe (o conforto), asseguraria a proximidade física para permitir que o pai respondesse às necessidades básicas da criança. Já o segundo polo, exercido pelo pai (ativação), permitiria a autodescoberta das próprias capacidades da criança, ambos facilitando a exploração do ambiente e permitindo o desenvolvimento de uma autoimagem positiva e confiança no pai. Da mesma forma, Lamb ${ }^{10}$ corrobora essas colocações, afirmando que o contato entre pai e criança se dá em maior escala física, aumenta com a idade e tende a ser mais intenso em locais públicos. Paquette ${ }^{20}$ relata ainda que as interações pai-criança ocorrem primariamente por meio da brincadeira, mais especificamente a turbulenta, encorajando a obediência e o desenvolvimento de competências competitivas nas crianças.

As especificidades dessas interações paicriança podem estar interferindo também no desenvolvimento motor das crianças. Um estudo realizado por Pilz e Schermann ${ }^{21}$, verificou a existência de uma relação entre o apoio/ cuidado paterno e o desenvolvimento neuropsicomotor da criança. Segundo os autores, o pai, além do provimento de condições materiais, ao proporcionar apoio emocional à mãe através de amor e companheirismo, auxilia na manutenção de um clima de harmonia e satisfação para a família, promovendo um desenvolvimento saudável para a criança. Além disso, o suporte que ele fornece à esposa influi no afeto materno, gerando um efeito protetor e melhorando a autoestima da mulher em sua função materna.

Em um estudo sobre a participação do pai nos cuidados da criança segundo a concep- 
ção das mães, Crepaldi, et $\mathrm{al}^{22}$ entrevistaram 30 famílias, divididas em dois grupos, metade cujos filhos frequentavam a creche e metade não. Os resultados encontrados evidenciaram que o pai aproveita diferentemente da mãe o tempo que passa com as crianças. A participação dos pais foi constatada no relato das mães entrevistadas, as quais descreveram seus companheiros como atuantes no cuidado de suas crianças, principalmente no que se refere às atividades conjuntas como sair, brincar, conversar e cantar. No entanto, tais atividades realizadas pelos pais não foram consideradas pelas mães como práticas de cuidado.

Os resultados do estudo demonstraram também uma diferença no grupo das mães de filhos que frequentavam a creche das que os filhos não frequentavam esta instituição. O primeiro grupo de mães descreveu como insuficientes os cuidados que o pai fornece aos filhos, mesmo declarando que ele ajuda em pelo menos dois cuidados por dia. As autoras descrevem como hipótese de explicação dessa percepção das mães o fato de elas não permanecerem o dia todo com o filho. Dessa forma, dividindo o cuidado com a creche, acabariam dispensando a ajuda do pai, ou ele próprio se veria dispensado dessa tarefa. Outra possibilidade seria que a mãe acaba não valorizando o cuidado que o pai fornece à criança, ao ponto de nem perceber quando ele o faz. Ao contrário, no grupo de mães cujos filhos não frequentavam a creche, as mães declararam que os pais participam mais dos cuidados com os filhos.

Outro dado importante da mesma pesquisa é com relação à percepção das mães sobre o carinho dispensado pelo pai aos filhos. As participantes foram solicitadas a julgar o companheiro como mais carinhoso, menos carinhoso, igual e diferente da mãe, sem neste último caso, terem delimitado tal diferença. Os resultados da pesquisa demonstraram que a soma das categorias "mais carinhoso do que a mãe" e "igual à mãe" representou a resposta de $56 \%$ das participantes. De acordo com as autoras, o fato de as mães terem considerado seus maridos como tanto ou mais carinhosos com os filhos do que elas mesmas pode significar uma mudança no papel do pai no contexto familiar.

Avaliando o comportamento parental a partir da percepção dos filhos, Goetz e Vieira ${ }^{23}$ investigaram crianças entre 10 e 11 anos de idade. O objetivo do estudo foi verificar como é desempenhado o papel real e ideal paterno e materno. Por real entende-se como as qualidades pertencentes a fenômenos que existem independentemente da nossa vontade, e por ideal, defini-se aquilo que só existe no pensamento que se referem a realidades diferentes das pertencentes às pessoas. Os resultados mostram que as crianças percebem o pai real (o que ele efetivamente é) muito distante em aspectos como cuidado, que implica higiene, alimentação, auxilio nas tarefas escolares, entre outros. Esse dado sugere que o papel real do pai deve abranger mais cuidados diretos, indiretos e interações sociais instrutivas e calorosas para que corresponda ao papel ideal que seus filhos the atribuem. No entanto, a percepção da mãe real aproxima-se da mãe ideal em aspectos como cuidado direto (higiene, alimentação, escolares e medicação, entre outras).

Grossmann e Grossmann ${ }^{25}$ investigaram a importância do apego parental em crianças a partir de dois estudos longitudinais. Os dados mostraram que crinças cujos pais as incentivaram a explorar o ambiente físico e que vivenciaram nas relações com seus cuidadores sentimentos de segurança e proteção, desenvolvem capacidade de se relacionar positivamente e têm mais condições de transferir essas experiências para outros relacionamentos íntimos na infância, adolescência e idade adulta.

Com base nos dados apresentados, pode-se concluir que a participação do pai no desenvolvimento infantil pode ser definida em termos de contribuição direta e indireta. Quando não há o contato físico direto, o pai participa na harmonização da família, contribuindo 
para que a mãe se envolva mais afetivamente com seus filhos. Além disso, o pai pode interferir na qualidade da dinâmica familiar, ao se envolver no trabalho doméstico, aliviando a carga de trabalho da mãe e transmitindo, a partir de seu exemplo, os valores e a cooperação.

Por outro lado, o pai pode contribuir de forma direta se envolvendo nos cuidados básicos dos seus filhos, ou seja, se responsabilizando pela higiene, alimentação e hora de dormir, mantendo dessa forma, um contato físico mais próximo e aumentando sua proximidade com seus filhos. Além disso, verifica-se que as interações pai-criança ocorrem predominantemente por meio de brincadeira turbulenta, o que pode ter um impacto direto sobre o desenvolvimento social e motor da criança. Por fim, vale destacar que a mãe possui um papel fundamental nesse processo de inclusão do pai, no sentido de auxiliar e incentivar, ajudando-o a desenvolver seu papel de cuidados tanto diretos quanto indiretos.

Procurou-se neste artigo discutir algumas variáveis que influenciam no cuidado parental, bem como o papel do pai no desenvolvimento infantil. O ponto mais importante dessa discussão é reconhecer que não existe apenas uma ou outra variável que a mais importante. Torna-se necessário considerar que muitos aspectos estão envolvidos no cuidado parental. Nesse sentido, tanto fatores filogenéticos como ontogenéticos, assim como características dos pais e também da criança, além do contexto cultural em que a família está inserida, tem influência no modo como a mãe e o pai irão cuidar dos seus filhos. Nesse sentido, o entendimento do comportamento parental eliciado a partir de elementos biológicos que foram selecionados devido a sua função de sobrevivência na espécie, apenas ganha sentido com a interação do contexto através da análise das tradições, práticas, condições socioeconômicas e outros aspectos socioculturais que o influenciam.

Com isso, pode-se discutir a influência dos aspectos culturais do desenvolvimento do vínculo entre pai e filho, fundamental para o bom desenvolvimento do recém-nascido. Percebe-se, assim, que a cultura tem um papel muito importante no que diz respeito ao cuidado e à responsividade paterna, na medida que são incentivados e reforçados os comportamentos masculinos nos cuidados aos lactentes. Para isso, a mãe também possui um papel muito importante, podendo auxiliar e incentivar o pai a desenvolver e manter esses comportamentos, o que poderá contribuir para a interação entre o pai e seus filhos ${ }^{26}$.

Para finalizar ressalta-se a necessidade de mais pesquisas que enfoquem o papel do pai no funcionamento familiar e no desenvolvimento infantil. Os resultados desses estudos poderão fornecer dados relevantes que poderão auxiliar na divulgação desse conhecimento para a comunidade em geral, por meio de políticas públicas, bem como meios de comunicação de massa. Nesse sentido, tais conhecimentos poderão atingir mais diretamente o pai, assim como promover a valorização de seu papel enquanto cuidador. 


\section{REFERÊNCIAS}

1. Prado AB. Semelhanças e diferenças entre homens e mulheres na compreensão do comportamento paterno [dissertação]. Florianópolis: Programa de Pós-Graduação em Psicologia, Universidade Federal de Santa Catarina; 2005.

2. Bussab VSR. Fatores hereditários e ambientais no desenvolvimento: a adoção de uma perspectiva interacionista. Psicol Reflex Crít. 2000; 13(2): 233-243.

3. Trivers PL. Parental investment and sexual selection. In: Campbell B. (Org.). Sexual selection and descent of man. Chicago:Aldine Press; 1972. p. 136-179.

4. Bussab VSR, Ribeiro FJR. Biologicamente cultural. In: Souza L, Freitas MFQ, Rodrigues MMP. (Orgs.). Psicologia Reflexões (im)pertinentes. São Paulo: Casa do Psicólogo; 1998. p. 195-224.

5. Seidl-de-Moura ML, Ribas RCJr, Piccinini CA, Bastos ACS, Magalhães CMC, Vieira ML, Salomão NMR, Silva AMPM, Silva AK. Conhecimento sobre desenvolvimento infantil em mães primíparas de diferentes centros urbanos do Brasil. Estud Psicol. 2004; 9(3): 421-429.

6. Prado AB, Vieira ML. Bases biológicas e influências culturais relacionadas ao comportamento parental. Rev Ciênc Hum. 2004; 34:313-334.

7. De Waal F. Eu Primata: porque somos como somos. São Paulo: Companhia das Letras; 2007.

8. Vieira ML, Piovanotti MRA. Relação entre a experiência parental e a presença do pai no cuidado parental em gerbilos da Mogólia (Meriones unguiculatus). Biotemas. 2004; 17(2): 149-176.

9. Keller H. Cultures of Infancy. Mahwah, NJ: Erlbaum; 2007.

10. Lamb ME. Fathers and child development: An introductory overview and guide. In: Lamb ME. (Org.). The role of the father in child development. New York: John Wiley \& Sons; 1997. p. 1-18.

11. Bandeira M, Goetz E, Vieira ML, Pontes F. O cuidado parental e o papel do pai no contexto familiar. In: Pontes FAR, Magalhães CMC, Brito RSC, Martin WLB. (Orgs.). Temas pertinentes à construção da psicologia contemporânea. Belém: Edufpa; 2005. p. 191-230.

12. Piccinini CA, Silva M, Gonçalves T, Lopes R, Tudge J. O envolvimento paterno durante a gestação. Psicol Reflex Crít. 2004; 17(3).

13. Maldonado MT, Dickstein J, Nahoum JC. Nós estamos grávidos. $10^{a}$ edição. São Paulo: Saraiva; 1997.

14. Nauhardt M. La concepetualizacion de la Paternidad. Boletim del Programa de Salud Reproductiva e Sociedad. El Colegio del Mexico; 1996.

15. Ribas AFP. Responsividade materna: articulações teóricas, discussões conceituais e uma investigação empírica em contexto urbano brasileiro [tese]. Rio de Janeiro: Programa de Pós-Graduação em Psicologia Social, Universidade do Estado do Rio de Janeiro; 2004.

16. Ribeiro FL, Bussab VSR, Otta E. De colo em colo, de berço em berço. In: Seidl de Moura ML. (Org.). O bebê do século XXI e a psicologia em desenvolvimento. São Paulo: Casa do psicólogo; 2004. p. 229-28.

17. Ribas AFP, Seidl de Moura ML, Ribas Jr RC. Responsividade materna: levantamento bibliográfico e discussão conceitual. Psicol Reflex Crít. 2003; 16(1): 137-145.

18. Klaus MH, Kennell JH, Klaus PH. Vínculo: construindo as bases para um apego seguro e para a independência. Porto Alegre: Artes Médicas; 2000.

19. Klaus M, Kennell P. Pais/Bebê: a formação do apego. Porto Alegre: Artes Médicas; 1992.

20. Paquette D. Theorizing the Father-Child Relationship: Mechanisms and Develop- 
mental Outcomes. Hum Develop. 2004; 47(4): 193-219.

21. Pilz EML, Schermann LB. Determinantes biológicos e ambientais no desenvolvimento neuropsicomotor em uma amostra de crianças de Canoas/RS. Ciênc Saúde Coletiva. 2007; 12(1): 181-190.

22. Crepaldi AM, Andreani G, Hammes SP, Ristof DC, Abreu RSA. Participação do pai nos cuidados da criança segundo a concepção de mães. Psicol Est. 2006; 11(3): 579-587.

23. Goetz ER, Vieira ML. Pai Real, Pai Ideal: O papel paterno no desenvolvimento infantil. Juruá; 2009.

24. Paquette D, Bigras A. The risky situation: a procedure for assessing the father-child activation relationship. Routledge; 2010, 180. (1\&2), 33-50.
25. Grossmann K, Grossmann KE. The impact of attachment to mother and father at an early age on children's psychosocial development through young adulthood. Rev ed. In: Tremblay RE, Barr RG, Peters $\mathrm{RDeV}$, Boivin M, eds. Encyclopedia on Early Childhood Development [online]. Montreal, Quebec: Centre of Excellence for Early Childhood Development; 2009:1-8. Available at: http://www.childencyclopedia.com/documents / GrossmannANGxp_rev.pdf. Accessed [13.03.2010].

26. Nunes SAN, Vieira ML. Fundamentos históricos e epistemológicos no estudo do comportamento paterno. Psicologia Argumento; 2009, 27, (57), 103-115.

Recebido em: 06/jum./10

Modificado em: 13/jul./10

Aceito em: 16/dez./10 